\title{
A Massive Denture Induced Hyperplastic Lesion in Maxilla- A Case Report
}

\author{
Muhammad Waseem Ullah Khan ${ }^{1}$ \\ BDS, FCPS \\ Muhammad Asif Mushtaq ${ }^{2}$ \\ BDS \\ Asif Ali Shah ${ }^{3}$ \\ BDS, MDS
}

Denture Induced Hyperplasia or Epulis fissuratum is a tumor-like reactive lesion of oral mucosa because of chronic irritation caused by ill-fitting dentures. It is mostly presented in female denture wearers with a predilection to maxilla. These lesions can be of varying sizes ranging from few centimeters to extensive involving the whole arch. These can be managed conservatively or by complete surgical excision depending upon the size and complexity of the lesion. In this case report, an enormous denture induced hyper-plastic lesion in an old male denture wearer is presented. The lesion was located in the maxillary left labial vestibule. This lesion was excised surgically, followed up for change of tissue conditioner up to one month. After completion of healing of wound, new complete denture was fabricated.

KEY WORDS: Denture induced hyperplasia,Epulis fissuratum,Denture fibroma.

HOW TO CITE: Khan MWU, Mushtaq MA, Shah AA. A massive denture induced hyperplastic lesion in maxilla-a case report. J Pak Dent Assoc 2019;28(1):47-49.

DOI: https://doi.org/10.25301/JPDA.281.47

Received: 15 September 2018, Accepted: 17 November 2018

\section{INTRODUCTION}

$\mathrm{E}$ pulis Fissuratum or Denture Induced Hyperplasia is a reactionary hyperplastic lesion of the oral cavity. The major etiologic factor is chronic trauma of low intensity from ill-fitting dentures or para functional habits. The appearance of the lesion is usually a symptomless single or multiple folds of hyperplastic tissue. These folds are lying in the alveolar vestibule with normal color, soft or firm consistency and smooth along the denture flange. Sometimes, severe ulceration or inflammation can occur in the depth of these folds. ${ }^{1,2}$

It is established that longer the duration of denture wearing, greater is the frequency of denture induced hyperplasia. This indicates that over the period of time, denture causes bone resorption leading to lose and ill-fitting dentures. This causes chronic low-grade trauma and inflammation of oral mucosa leading to Epulis Fissuratum. ${ }^{3}$ Chronic nature of the problem suggests that discomfort is usually not a prominent feature and patient continue to use the problematic denture until hyperplastic tissue takes a

1. Assistant Professor, Department of Prosthodontics, de'Montmorency College of Dentistry/ Punjab Dental Hospital, Lahore.

2. FCPS Resident Prosthodontics, Department of Prosthodontics de'Montmorency College of Dentistry/ Punjab Dental Hospital, Lahore.

3. Professor of Prosthodontics, Department of Prosthodontics, de'Montmorency College of Dentistry/ Punjab Dental Hospital, Lahore.

Corresponding author: "Dr. Muhammad Asif Mushtaq" < dr.asif100@yahoo.com > considerable size. Patients become aware and seek treatment for the condition usually because of the size of growth rather than any pain or discomfort. ${ }^{4}$

This condition often occurs in middle-aged and older. It is reported in $5-10 \%$ of individuals wearing dentures and it occurs more frequently in the anterior part of the jaw than the posterior. It is more common in women than men. It is more common in maxilla than mandible. The size of the lesion can be ranging from $1 \mathrm{~cm}$ to more extensive involving the complete vestibule of the jaw., Depending upon the size of the lesion, denture induced hyperplasia can be treated conservatively or surgically excised. ${ }^{6}$ Rosenquet has mentioned that chronic trauma from ill-fitting dentures with sharp borders can also cause oral carcinoma. Therefore, ill-fit dentures and sharp borders of dentures should never be left unaddressed.?

\section{CASE REPORT}

A 65-year-old male patient presented to the OPD of Department of Prosthodontics, Punjab Dental Hospital, Lahore with the complaint of painless swelling in the upper arch in left labial vestibule (figure 1). The patient had been wearing his previous set of upper and lower complete dentures for the last five years but did not notice any swelling till the last six months. On examination of denture, it was noticed that the border of left labial flange of the upper 


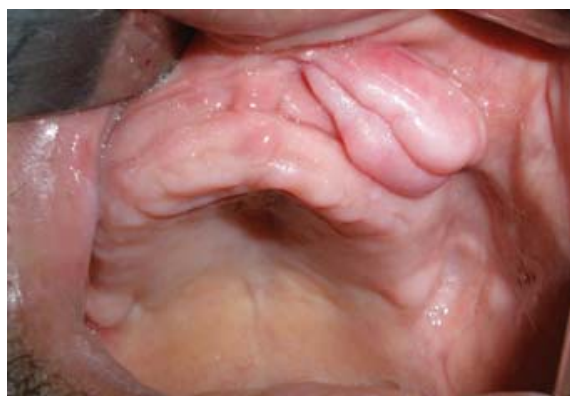

Fiq 1

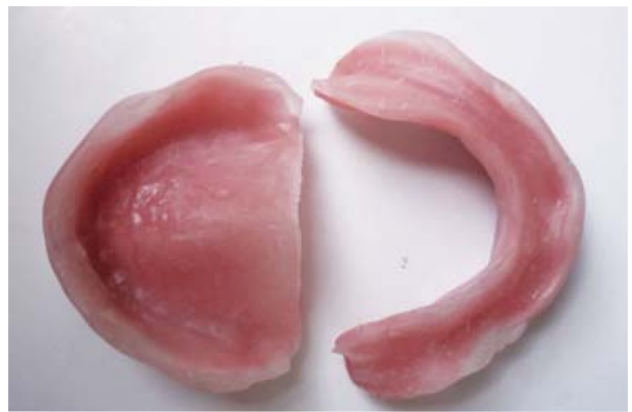

Fiq 4

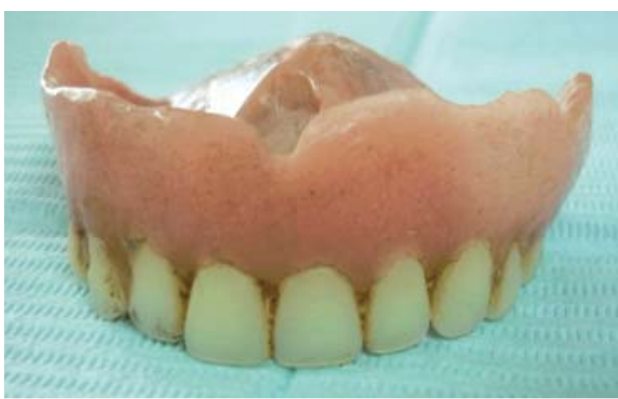

Fiq 2

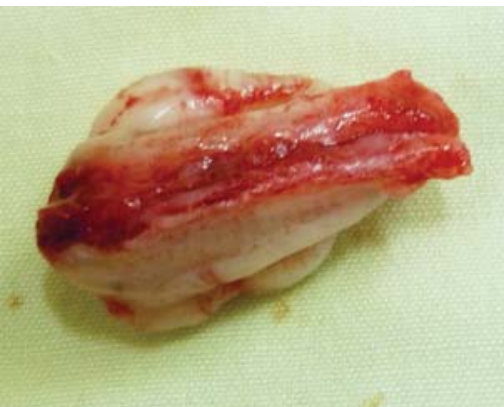

Fiq 5

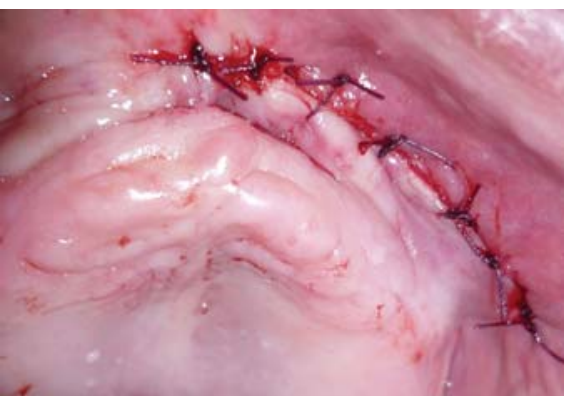

Fiq 3 complete removable denture was sharp and overextended causing chronic irritation and trauma to non-keratinized soft tissue of maxillary left labial vestibule (figure 2). Denture hygiene was average with signs of tooth wear on the occlusal surfaces of acrylic teeth. Medical history was non-significant for the lesion. Patient was suffering from controlled type 2 Diabetes Mellitus and on oral hypoglycemic. He had no injurious oral habits like tobacco chewing or smoking. Extra oral examination revealed no abnormal facial features. Intraoral examination revealed folds of hyperplastic tissue in the left maxillary labial vestibule extending from the left central incisor region to the second premolar area with maxillary denture flange lying medial to the tissue folds. The tissue folds were of normal color and firm. They were non-tender and mobile. There was no ulcer in the tissue folds or the labial vestibule. Palatal mucosa was normal and there was no abnormal findings intra orally. Keeping in view of clinical examination and history, provisional diagnosis of Denture Induced Hyperplasia or Epulis Fissuratum was made. Patient was instructed to discontinue the use of denture and oral hygiene instructions were given. Considering the extensiveness of the hyperplastic tissue, it was obvious that conservative measures will not completely resolve the lesion. So, a conventional surgical resection of the tissue was planned. Local anesthesia containing lidocaine $2 \%$ and adrenaline 1:80,000 was administered for anterior superior alveolar, infra orbital and lesser palatine nerve. Outline of the resection was made with no. 15 surgical blade along the length of the hyperplastic tissue in a wedge shape. The resection was done from the midline to the first molar area in the left maxillary labial vestibule and primary closure was done using 3-0 Vicryl sutures (figure 3). Postoperative instructions were given to the patient along with antibiotics and analgesics. The sharp left labial flange of maxillary complete denture was rounded off and relined with tissue conditioner and given to the patient to wear it as surgical splint (figure 4). The excised tissue was submitted for histopathological evaluation which confirmed the diagnosis (figure 5). At first follow up visit after seven days, tissue healing was good. Tissue conditioner was replaced at the same appointment. Later on, patient was recalled after every one week up to one month to replace the tissue conditioner. Impressions were taken after one month of surgery for the fabrication of new dentures. The patient is on six monthly follow up and no recurrence is found till date. Figure 6 and 7 represent the presentation of patient at the time of initial reporting to the hospital and at the time of delivery of new set of dentures.

\section{DISCUSSION}

Denture irritation hyperplasia is a type of Reactive Localized Inflammatory Lesion of the oral mucosa. The etiologic factors involved in the development of such lesions can be low grade chronic irritation to the oral mucosa e.g. sharp edges of grossly carious teeth, dental plaque and calculus, faulty dental restorations, ill-fitting dentures, 
chronic biting habits and food impaction. Systemic factors include hormonal changes. ${ }^{8}$ Denture irritation hyperplasia can be the result of ill-fitting denture, poor oral hygiene, all day-night wearing of denture, smoking and age related changes. ${ }^{5}$ Residual Ridge Resorption is also very important etiologic factor for denture irritation hyperplasia. Gradual progression of residual ridge resorption induces decrease in ridge height and the denture flanges overextend into the vestibule. Chronic trauma from extended denture flanges into the vestibule over a long period of time causes reparative response, leading to fibrous tissue hyperplasia. ${ }^{9}$

In our case report, overextended and sharp left labial flange of maxillary complete denture and poor oral hygiene was the etiologic factor. Macedo Firoozmand et al had mentioned in their study that $78 \%$ of denture wearer were female that presented with denture irritation hyperplasia mostly in maxilla. ${ }^{10}$ Although in literature, it has been mentioned that irritation hyperplasia has female predilection, but our case report is on a male patient. ${ }^{10,11}$

Differential Diagnosis of denture irritation hyperplasia include denture fibroma, benign mesenchymal tumor and minor salivary gland tumour. ${ }^{5}$

Treatment options for denture induced hyperplasia include conservative therapy and surgical excision. Conservative measures include discontinue denture wearing for some time, placement of tissue conditioner on the tissue surface of denture and correction of denture faults. These measures are effective only in case of small lesions. ${ }^{4}$ Surgical treatment can be conventional surgical supra-periosteal excision or advanced surgical techniques e.g. electro surgery, cryosurgery and laser surgery. ${ }^{5,12}$ In our reported case, conventional surgical supra-periosteal excision was done. Although in most cases, histopathology reports of the excised tissue show inflammatory and fibrous changes, but still every specimen of excised issue should be submitted for histopathology analysis.

\section{CONCLUSION}

A case of denture induced hyperplasia was treated successfully. The etiology of the condition is discussed in detail and emphasis on the need for treatment is given. Patient should be educated about the benign nature of the lesion and complete oral hygiene instructions should be given to the patient to avoid recurrence. Importance of removal of denture at night and regular follow up with dentist should be advised.

\section{CONFLICT OF INTEREST}

None to declare

\section{REFERENCES}

1. Mortazavi H, Safi Y, Baharvand M, Rahmani S, Jafari S. Peripheral Exophytic Oral Lesions: A Clinical Decision Tree. Int J Dent 2017; 9193831:1-19.

2. Canger EM, Celenk P, Kayipmaz S. Denture-related hyperplasia: a clinical study of a Turkish population group. Brazilian Dent J 2009;20:243-48.

https://doi.org/10.1590/S0103-64402009000300013

3. Coelho CM, Sousa YT, Dare AM. Denture-related oral mucosal lesions in a Brazilian school of dentistry. J Oral Rehab 2004;31:13539.

https://doi.org/10.1111/j.1365-2842.2004.01115.x

4. Veena KM, Jagadishchandra H, Sequria J, Hameed SK, Chatra L, Shenai P. An extensive denture induced hyperplasia of maxilla. Annals of Med Health Sci Res 2013;3:7-9.

https://doi.org/10.4103/2141-9248.121208

5. Mortazavi H, Khalighi HR, Jafari S, Baharvand M. Epulis fissuratum in the soft palate: Report of a case in a very rare location. Dent Hypotheses 2016;1;7:67-69.

6. Mohan RP, Verma S, Singh U, Agarwal N. Epulis fissuratum: consequence of ill-fitting prosthesis. Brit Med J Case Reports 2013: $1-2$

https://doi.org/10.1136/bcr-2013-200054

7. Rosenquist K. Risk factors in oral and oropharyngeal squamous cell carcinoma: a population-based case-control study in southern Sweden. Swedish Dent J. Supplement 2005;179:1-66.

8. Awange DO, Wakoli KA, Onyango JF, Chindia ML, Dimba EO, Guthua SW. Reactive localised inflammatory hyperplasia of the oral mucosa. East Afri Med J 2009;86:79-82.

https://doi.org/10.4314/eamj.v86i2.46939

9. Esmeili T, Lozada-Nur F, Epstein J. Common benign oral soft tissue masses. Dent Clinics 2005;49:223-40.

https://doi.org/10.1016/j.cden.2004.07.001

10. Macedo Firoozmand L, Dias Almeida J, Guimarães Cabral LA. Study of denture-induced fibrous hyperplasia cases diagnosed from 1979 to 2001. Quintessence Int 2005;36:825-29.

11. Cooper LF. The current and future treatment of edentulism. Journal of Prosthodontics: Implant, Estheti Reconst Dent 2009;18:116-22. https://doi.org/10.1111/j.1532-849X.2009.00441.x

12. Infante-Cossio P, Martinez-de-Fuentes R, Torres-Carranza E, Gutierrez-Perez JL. Inflammatory papillary hyperplasia of the palate: treatment with carbon dioxide laser, followed by restoration with an implant-supported prosthesis. Brit J Oral Maxillofac Surg. 2007; 45: 658-60.

https://doi.org/10.1016/j.bjoms.2006.08.005 